\title{
A PHONETIC STUDY OF FOCUS IN INTRANSITIVE VERB SENTENCES
}

\author{
Steve Hoskins \\ email: hoskins@asel.udel.edu \\ Applied Science and Engineering Laboratories \\ University of Delaware/ A. I. duPont Institute \\ Wilmington, Delaware USA 19899
}

\begin{abstract}
In English, focus is one of the factors determining the prosodic characteristics of an utterance. Some recent linguistic analyses (Selkirk 1995) claim that focus is represented in the phonology by pitch accents, and the placement of these accents is determined by both the type of focus (broad, narrow), syntactic structure, and other factors such as verbargument structure. In this study, an experiment was conducted to test the interaction of focus types and different argument structures within sentences with intransitive verbs. A prosodic analysis was conducted, durations and fundamental frequency of the subject nouns and verbs of these sentences were measured. The prosodic and acoustic analyses support Selkirk (1995): specifically, the verb may be deaccented under broad focus when the subject is a theme (in unaccusatives and passives) but not when an agent (unergatives). Also, there is a tendency for the nuclear accented word to have a greater duration and Fo under narrow focus, which seems to be related to a more frequent occurance of the $\mathrm{L}+\mathrm{H}^{*}$ pitch accent for this condition.
\end{abstract}

\section{INTRODUCTION}

Focus refers to the portion of a sentence that is meant to be salient for semantic reasons; for example highlighting new information in the discourse or for responses to wh-questions, such as the example below (note: Capitals indicate a greater prominence on an individual word, which according to Selkirk 1995 represents a $\mathrm{H}^{*}$ pitch accent)
(1) (a) What did Mary do?
Mary bought a BOOK
(b) What did Mary buy?
Mary bought a BOOK
(c) Who bought a book?
MARY bought a book.

A final prominence (nuclear accent) is compatible with the broad focus on the verb phrase (VP) of (1a) or the narrower focus on the noun phrase (NP) of (1b). However, a nuclear accent on the subject NP is only compatible with a narrow focus on the subject, as in (1c), and could never be construed as being an appropriate response to a the questions of (1a) or (1b). Thus, placement of the nuclear accent constrains the possible focus interpretations [6][8[11][13][14].

However, a number of sources ([4][11][12][13][14]) claim there are cases where an early nuclear accent may signal a broad focus:
(2) (a) What happened?
(b) What's new? CLASSES were cancelled
(c) What happened? John's WORKING

Selkirk (1995) [13] predicts that the early accents in (2a) and (2b) follow from a theory of focus projection sensitive to verb-argument structure: (2a) and (2b) are unaccusative and passive structures respectively, both having a theme subject, and (2c) is an unergative, with an agent subject. According to this theory, marking a theme (internal argument) of a verb (whether in subject or object position) with a pitch accent is compatible with interpreting both the verb and the argument as part of a focus. This theory also predicts that a narrow focus on the argument may be prosodically identical to a broad focus on the verb-argument complex.

While these cases are much discussed in the linguistics focus literature, no empirical evidence to date has been provided ${ }^{1}$. The purpose of this study is to provide such data: by testing these exceptional cases of focus, examining the resulting pitch accent distribution, and measuring the acoustic characteristics of these foci, in terms of Fo and duration.

\section{MATERIALS AND METHODS}

\subsection{Sentence Materials}

Nine basic sentences, three unaccusative (a-c), three passive (d-f), and three unergative (g-i), were constructed:

(3) (a) I think his dinner burned.

(b) I think his water boiled.

(c) I think his neighbor died.

(d) I think his ladder was moved.

(e) I think his letter was mailed.

(f) I think his lumber was hauled.

(g) I think his daughter jogged.

(h) I think his lawyer lied

(i) I think his mother dozed.

Each sentence was matched with three focus priming questions; one question prompts for broad focus, one for narrow focus on the embedded subject, and one for the embedded verb

(4) (a) What happened while he was gone?

NARROW-SUB

(c) What happened to his dinner? NARROW-VERB

Answer: I think his dinner burned

An equal number of filler sentences, with three different focus questions, were also constructed for the experiment.

Based on the predictions of Selkirk (1995) [14], the following table shows the expected pitch accent distribution on the embedded subject and verb.

Table 1: Pitch Accents on Subj, Verb

\begin{tabular}{|c|c|c|c|}
\hline FOCUS & Unergative & Unaccus. & Passive \\
\hline Broad & $\mathrm{H}^{*}, \mathrm{H}^{*} \mathrm{~L}-$ & $\overline{\mathrm{H}^{*} \mathrm{~L}-, \mathrm{X}}$ & $\bar{H} * \mathrm{~L}-, \mathrm{X}$ \\
\hline Narrow (Subj.) & $\mathrm{H}^{*} \mathrm{~L}-, \mathrm{X}$ & $\mathrm{H}^{*} \mathrm{~L}-, \mathrm{X}$ & $\mathrm{H}^{*} \mathrm{~L}-, \mathrm{X}$ \\
\hline Narrow (Verb) & $\mathrm{X}, \mathrm{H}^{*} \mathrm{~L}-$ & $\mathrm{X}, \mathrm{H}^{*} \mathrm{~L}-$ & $\mathrm{X}, \mathrm{H}^{*} \mathrm{~L}-$ \\
\hline
\end{tabular}

1. see [2][3][6] for studies on transitive verb sentences 
Note that in Table 1, the first pitch accent is for the subject noun, the second for the intransitive verb. No pitch accent is designated by " $\mathrm{X}$ ". The pitch accent in the nuclear position is followed by the phrase accent "L-"

\subsection{Subjects and Procedure}

Fifteen subjects, eleven male and four female, all employees of ASEL and/or graduate students from the University of Delware, participated in the study. All were native speakers of American English and were without speech or hearing impairments.

The subjects were recorded reading a sequence of the 27 target sentences and 27 fillers in four blocks; within each block the sentences and fillers were randomized, each subject receiving different random presentations. For every sentence, the focus priming question was presented binaurally (via headphones) and the target sentence was presented visually (on an EMS touch screen panel). The entire experiment was controlled by software residing on a GV386 PC compatible. Subjects were instructed to read the target sentence as a response to the preceding question. The recordings were made in a sound dampened booth; both speech and electroglottograph (EGG) data were recorded.

\subsection{Analysis}

The speech and EGG recordings were digitized at $16 \mathrm{kHz}$ with appropriate prefiltering. Of the four repetitions for each sentence, the last three acceptable ones were kept (repetitions with speech errors were discarded). For every sentence, the speech and EGG data were incorporated into one multichannel waveform file. Using a waveform editor, the durations of the embedded subject and intransitive verb were marked and measured. Pitch tracking software was used to determine the Fo contour of each sentence, and the results were post-processed to produce a peak Fo for the embedded subject, a peak Fo for the intransitive verb, and an average Fo for the sentence. The Peak Fo values were normalized by the average Fo value.

Within subjects repeated measures ANOVA were performed on the subject and verb durations and normalized Fo. Planned comparisons (orthogonal Helmert contrast codes) were used to determine the significant effects:

(5) FOC1 NV vs average(NS,B)

FOC2 NS vs B

STR1 unergative vs. average (unaccus.,passive)

STR2 unaccusative vs. passive

NS $=$ Narrow Focus on Subject

$\mathrm{NV}=$ Narrow Focus on Verb

$\mathrm{B}=$ Broad Focus on Subject+Verb

A TOBI prosodic analysis of the corpus was also conducted.

\section{RESULTS}

Tables 2-7 show the results of the ANOVA and TOBI analyses. In Table 4, the values represent the means for all three repetitions averaged over the 15 subjects. Tables 5-7 show the percent of the total pitch accents. Figures 1-2 show plots of Fo and durations.
Table 2: ANOVA Results - Subject

\begin{tabular}{|c|c|c|}
\hline CODE & $\begin{array}{l}\text { DURATION } \\
\mathrm{F}(1,14) / \mathrm{Pr}>\mathrm{F}\end{array}$ & $\begin{array}{c}\text { Fo } \\
F(1,14) / \operatorname{Pr}>F\end{array}$ \\
\hline $\mathrm{FOCl}$ & $27.4 / 0.001$ & $8.13 / 0.0128$ \\
\hline FOC2 & $17.81 / 0.0009$ & $\begin{array}{lll}76.49 / & 0.0001\end{array}$ \\
\hline STR1 & $33.57 / 0.0001$ & $15.18 / 0.0016$ \\
\hline STR2 & $5.35 / \quad 0.0364$ & $1.20 / \quad 0.2924$ \\
\hline FOC $1 *$ STR 1 & $0.00 / 1.00$ & $24.3 / \quad 0.0002$ \\
\hline FOC1*STR2 & $0.53 / \quad 0.4776$ & $3.83 / \quad 0.0707$ \\
\hline FOC2*STR1 & $11.03 / 0.005$ & $36.61 / 0.0001$ \\
\hline FOC2*STR2 & $\begin{array}{ll}2.16 / & 0.1635 \\
\end{array}$ & 0.0685 \\
\hline
\end{tabular}

Table 3: ANOVA Results - Verb

\begin{tabular}{l|ll|ll}
\multicolumn{1}{c|}{ CODE } & \multicolumn{2}{|c|}{ DURATION } & \multicolumn{2}{c}{ Fo } \\
& $\mathrm{F}(1,14) / \mathrm{Pr}>\mathrm{F}$ & \multicolumn{2}{c}{$\mathrm{F}(1,14) / \mathrm{Pr}>\mathrm{F}$} \\
\hline FOC1 & $244.99 / 0.0001$ & $35.33 /$ & 0.0001 \\
\hline FOC2 & $41.96 /$ & 0.0001 & $64.99 /$ & 0.0001 \\
\hline STR1 & $320.56 /$ & 0.0001 & $58.58 /$ & 0.0001 \\
\hline STR2 & $205.14 /$ & 0.0001 & $0.87 /$ & 0.3657 \\
\hline FOC1*STR1 & $1.76 /$ & 0.2055 & $3.01 /$ & 0.1049 \\
\hline FOC1*STR2 & $5.24 /$ & 0.038 & $0.00 /$ & 1.00 \\
\hline FOC2*STR1 & $18.49 /$ & 0.0007 & $14.63 /$ & 0.002 \\
\hline FOC2*STR2 & $0.00 /$ & 1.00 & $1.90 /$ & 0.19 \\
\hline
\end{tabular}

Table 4: Durations and Normalized Fo

\begin{tabular}{l|l|l|l|l|l}
\hline Focus & Struct. & $\begin{array}{c}\text { Duration } \\
\text { Subj }\end{array}$ & $\begin{array}{c}\text { Duration } \\
\text { Verb }\end{array}$ & $\begin{array}{c}\text { Fo } \\
(\%) \\
\text { Subj }\end{array}$ & $\begin{array}{c}\text { Fo } \\
(\%) \\
\text { Verb }\end{array}$ \\
\hline B & UNERG & $328.3 \mathrm{mS}$ & $498.3 \mathrm{mS}$ & 111 & 104 \\
\hline B & UNACC & $314.0 \mathrm{mS}$ & $426.9 \mathrm{mS}$ & 124 & 88 \\
\hline B & PASSIVE & $305.4 \mathrm{mS}$ & $395.9 \mathrm{mS}$ & 125 & 90 \\
\hline NS & UNERG & $350.2 \mathrm{mS}$ & $444.8 \mathrm{mS}$ & 126 & 82 \\
\hline NS & UNACC & $328.3 \mathrm{mS}$ & $410.8 \mathrm{mS}$ & 129 & 82 \\
\hline NS & PASSIVE & $315.2 \mathrm{mS}$ & $378.0 \mathrm{mS}$ & 129 & 82 \\
\hline NV & UNERG & $311.2 \mathrm{mS}$ & $514.0 \mathrm{mS}$ & 101 & 109 \\
\hline NV & UNACC & $311.2 \mathrm{mS}$ & $479.2 \mathrm{mS}$ & 106 & 112 \\
\hline NV & PASSIVE & $281.6 \mathrm{mS}$ & $436.8 \mathrm{mS}$ & 108 & 112 \\
\hline
\end{tabular}

Table 5: Nuclear Accent on Subject (\%)

\begin{tabular}{l|l|l|l}
\hline & UNACC. & PASS. & UNERG \\
\hline BROAD & 71.1 & 58.5 & 8.2 \\
\hline N SUBJ & 100 & 100 & 100 \\
\hline N VERB & 0 & 0 & 0 \\
\hline
\end{tabular}

Table 6: Accent Type on Subject (\%)

\begin{tabular}{l|l|l|l|l|l}
\hline Focus/Structure & $! \mathrm{H}^{*}$ & $\mathrm{~L}+\mathrm{H}$ & $\mathrm{H}^{*}$ & $\mathrm{~L}^{*}$ & none \\
\hline Broad - Unacc. & 3.0 & 28.2 & 61.5 & 0.0 & 7.4 \\
\hline Broad - Passive & 3.0 & 34.8 & 55.6 & 0.0 & 6.7 \\
\hline Broad - Unerg. & 11.1 & 4.4 & 58.5 & 3.0 & 23.0 \\
\hline N Subj - Unacc. & 0.0 & 61.5 & 34.1 & 0.0 & 0.0 \\
\hline N Subj - Pass. & 0.7 & 71.1 & 28.2 & 0.0 & 0.0 \\
\hline N Subj - Unerg. & 0.0 & 67.4 & 32.6 & 0.0 & 0.0 \\
\hline N Verb - Unacc. & 8.9 & 0.7 & 30.4 & 11.9 & 48.5 \\
\hline N Verb - Pass. & 11.9 & 1.5 & 45.9 & 12.6 & 28.2 \\
\hline N Verb - Unerg. & 8.2 & 2.0 & 24.5 & 14.8 & 45.2 \\
\hline
\end{tabular}


Table 7: Accent Type on Verb (\%)

\begin{tabular}{l|l|l|l|l|l}
\hline Focus/Structure & \multicolumn{1}{|c|}{$\mathrm{H}^{*}$} & $\mathrm{~L}+\mathrm{H}$ & $\mathrm{H}^{*}$ & $\mathrm{~L}^{*}$ & none \\
\hline Broad - Unacc. & 2.2 & 0.0 & 26.7 & 0.0 & 71.1 \\
\hline Broad - Pass. & 2.2 & 3.7 & 35.6 & 0.0 & 58.5 \\
\hline Broad - Unerg. & 11.1 & 2.9 & 77.8 & 0.0 & 8.2 \\
\hline N Subj. - Unacc. & 0.0 & 0.0 & 0.0 & 0.0 & 100 \\
\hline N Subj. - Unerg. & 0.0 & 0.0 & 0.0 & 0.0 & 100 \\
\hline N Subj. - Pass. & 0.0 & 0.0 & 0.0 & 0.0 & 100 \\
\hline N Verb - Unacc. & 8.9 & 35.6 & 55.6 & 0.0 & 0.0 \\
\hline N Verb - Pass. & 11.9 & 29.6 & 58.5 & 0.0 & 0.0 \\
\hline N Verb - Unerg. & 8.9 & 31.1 & 43.6 & 0.0 & 0.0 \\
\hline
\end{tabular}

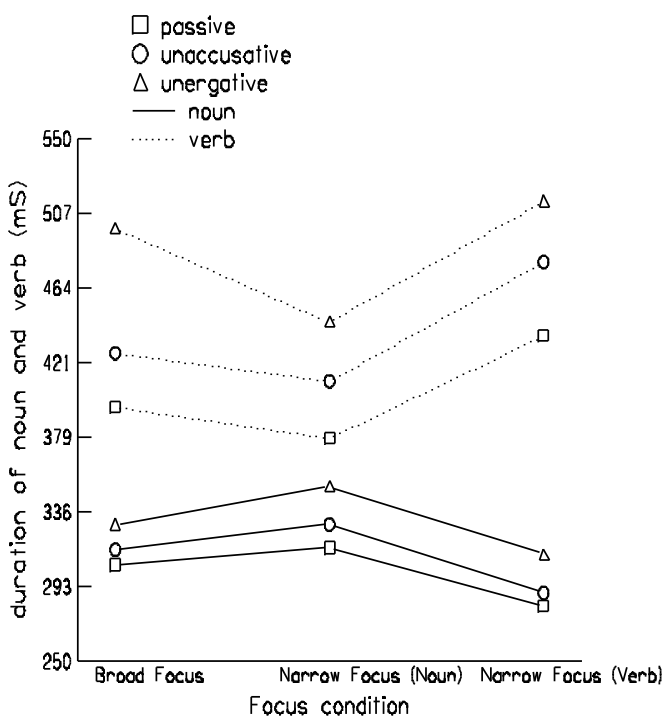

FIG 1. Duration of Verb and Noun (ms)

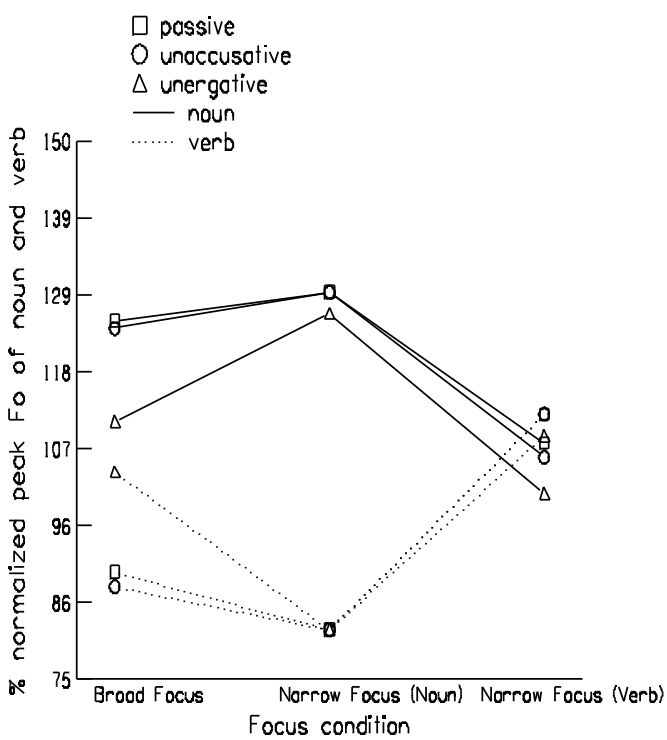

FIG 2. \% normalized peok Fo of Verb and Noun

\section{DISCUSSION}

For both the subject and the verb measurements, the results of the ANOVA were highly significant for focus (FOC1 and FOC2), structure (STR1), and the interaction (FOC2*STR1). In addition, the TOBI analysis results show a pitch accent distribution sensitive to both focus and structure, with a pattern in accordance with the acoustic analyses.

The most salient and consistent results were the effects of narrow focus. From Tables 5-7 it is clear that the nuclear pitch accent location is invariant for the narrow focus conditions; when focus was on the subject alone, the subject received the nuclear accent, and likewise for the intransitive verb. The interesting case is the broad focus condition. Here, by inspecting Table 5, it is apparent that the verb-argument structure affected the location of the nuclear accent. As predicted by Selkirk (1995), the intransitive verbs with a theme subject (unaccusatives, passives) were frequently deaccented $(71.1 \%$ and $58.5 \%$ respectively), while the unergatives were only rarely deaccented $(8.2 \%)$. This structure-dependent behavior is also reflected in the significant interactions of the acoustic analyses, which follow.

In general, the acoustic analyses revealed the following results. The durations and Fo on the subject noun were greatest under the narrow focus/subject condition, least under the narrow focus/ verb condition, and the behavior under broad focus depended on the argument structure. For the verb, the exact opposite was true; the durations and peak F0 values were the least under the narrow focus/subject condition, greatest under the narrow focus/verb condition, and once again were structure dependent for broad focus. As demonstrated by Eady and Cooper (1986)[2][3], the greater durations and Fo are due to local effects of the location of the focus; this is interpreted here as the phonetic realization of the nuclear pitch accent and boundary tone ( $\mathrm{H}^{*} \mathrm{~L}-$ or $\left.\mathrm{L}+\mathrm{H}^{*} \mathrm{~L}-\right)$.

The effect of FOC1 (comparing the narrow focus on the verb against the other two foci) can be seen by inspecting figures 1-2 and tables 6-7; with the narrow focus on the verb, the peak Fo on the intransitive verb was higher and the durations longer. Conversely, the peak Fo was lower and the durations shorter on the subject noun for this condition. These acoustic measurement differences match the pitch accent distributions: for narrow verb focus, the verb always had a pitch accent (either $\mathrm{H}^{*}$ or $\mathrm{L}+\mathrm{H}^{*}$ ) and often the subject had no accent at all, while this was not the case for the other two focus conditions.

The effects of FOC 2 and FOC2*STR 1 clearly show the interaction of structure with focus. FOC2 compares the broad and narrow subject foci; STR1 compares the unergatives with the other two structures. In general, the narrow subject focus condition measurements showed greater durations and peak Fo values for the subject noun, and lesser values for the intransitive verb. This is result of the narrow focus forcing a nuclear accent on the subject noun, deaccenting the intransitive verb. The difference between narrow and broad focus was markedly more dramatic for the unergative structures than for the others. The Fo on the verb was substantially greater for the unergative structure under broad focus (104\% vs $89 \%$ ). This seems to be due to the fact that the broad focus nuclear accent was usually on the verb for 
unergatives (91.8\%) but only occasionally on the verb for the other two structures (35.2\%). The peak Fo on the subject noun was somewhat lower for the unergative condition for broad focus $(111 \%$ vs $125 \%)$. Table 6 shows that the subject was accented with $\mathrm{H}^{*}, ! \mathrm{H}^{*}$, or $\mathrm{L}+\mathrm{H}^{*}$ less frequently for the unergative condition $(74 \%)$ than for the other two $(92.9 \%)$; this may account for the overall lower peak Fo values.

Turning now to the unaccusative and passives, there were small differences between broad and narrow focus; the narrow focus peak Fo and duration values were slightly greater for the noun and lesser for the verb. Again, this seems to be the result of the pitch accent differences, specifically the complete lack of an accent on the intransitive verb for narrow focus (but not for broad focus). Concerning the subject noun, there was more often a $\mathrm{L}+\mathrm{H}^{*}$ nuclear pitch accent for the narrow focus condition $(66.3 \%)$ than for the broad $(31.5 \%)$, and the phonetic difference between $\mathrm{L}+\mathrm{H}^{*}$ and $\mathrm{H}^{*}$ or ! $\mathrm{H}^{*}$ may be reflected in the greater $\mathrm{F} 0$ peak (one of the differences between these two accents is expanded pitch range for $\left.\mathrm{L}+\mathrm{H}^{*}[1]\right)$.

The prosodic analysis revealed a few findings that were unexpected. For example, the presence of the $\mathrm{L}+\mathrm{H}^{*}$ accent was more frequent than one would predict, since according to Pierrehumbert and Hirschberg [10] this accent is associated with contrastive meaning, and the experiment was designed to not set up contrasts in the focus priming questions. As noted above, the use of the $\mathrm{L}+\mathrm{H}^{*}$ accent was much more common for the narrow focus conditions (especially the narrow subject focus). In addition, the subject noun was frequently accented $\left(\mathrm{H}^{*}\right.$, more rarely ! $\mathrm{H}$ or $\left.\mathrm{L}+\mathrm{H}^{*}\right)$ when outside of the focus, under the narrow verb focus condition $(46.3 \%)$ The presence of this accent is not predicted by some linguistic theories of focus and pitch accent [11][13][14]; the subject noun for the narrow verb focus would be considered given [9] or presupposed [7], and thus would be predicted to either be without a pitch accent [13] or perhaps with a $\mathrm{L}^{*}$ accent [10]. Here, roughly half of the time subjects produced a pitch accent on a given item preceding the focus, while a given item following the focus (the verb in the narrow subject focus condition) was never accented. The compatibility of pitch accents with given information under some circumstances has been noted by Fuchs (1984) [5] and Nooteboom and Kruyt (1987) [9] (for Dutch). These authors assumed that the accent on the given item (always a subject) was a marker for the "theme" or "topic" of the sentence. Further investigation is necessary to determine if this type of accent is indeed a signal for topic structure, or is instead reflective of something else, for example a tendancy to accent the final content word in a phonological phrase.

\section{CONCLUSIONS}

This study has shown conclusively that the predictions of Selkirk (1995) [14] concerning early accented intransitive sentences have been verified by the results of a speech production experiment. As predicted, under broad focus unaccusatives and passive structures tend to have deaccented verbs, while for unergatives, the verbs are usually accented. The focus and structure sensitive distribution of the nuclear accents matches the conditions where the acoustic measurements show greater durations and Fo values. There are also subtler differences between broad and narrow focus, reflected mostly in the frequency and type of pitch accent present $\left(\mathrm{H}^{*}\right.$ vs $\left.\mathrm{L}+\mathrm{H}^{*}\right)$. Frequent pitch accents on the subject noun under all conditions indicate that content words outside of the focus (in the prenuclear position only) may be accented, although it is not known whether this is due to thematic or structural reasons.

\section{ACKNOWLEDGEMENTS}

This work was supported in part by NIDRR grant \#H133E30010 to the Applied Sciences and Engineering Laboratories of the Univ. of Delaware and the A.I. Dupont Institute.

\section{REFERENCES}

[1] Ayers, Gayle (1996) Nuclear Accent Types and Prominence: Some Psycholinguistic Experiments. OSDL: Ohio State

[2] Eady, Stephen, W. Cooper, G. Klouda, P. Mueller, D. Lotts. (1986) Acoustical characteristics of sentential focus: narrow vs. broad and single vs. dual. Language and Speech 29:3 pp 233-251.

[3] Eady, Stephen and W. Cooper (1986) Speech intonation and focus location in matched statements and questions. JASA 80(2), pp 402 - 415.

[4] Faber, David. (1987). The accentuation of intransitive sentences in English. Linguistics 23. pp 341-358

[5] Fuchs, A. (1984) Deaccenting and default accent. In Intonation, accent, and rhythm, eds; D. Gibbon and H. Richter. DeGruyter, NY. pp 134-164

[6] Gussenhoven, Carlos (1983), On the Grammar and Semantics of Sentence Accents. Dordrecht:Foris

[7] Jackendoff, Ray (1972). Semantic interpretation in generative grammar. Cambridge, MA: MIT Press

[8 ] Ladd, D. Robert (1980) The structure of intonational meaning. Bloomington: Indiana University Press.

[9] Nooteboom, S.G. and Kruyt, J.G. (1987) Accents, focus distribution, and the perceived distribution of given and new information: An experiment. JASA 82(5) pp. 1512-1524

[10] Pierrehumbert, Janet and Hirschberg, Julia (1990). The meaning of intonation contours in the interpretation of discouse. In Intentions and communication. eds P. Cohen, J Morgan, M. Pollack. Cambridge: MIT Press.

[11] Rochemont, Michael (1986) Focus in Generative Grammar John Benjamins: Amsterdam

[12] Schmerling, Susan (1976) Aspects of English sentence stress. Austin: Texas University Press

[13] Selkirk, E.O. (1984) Phonology and Syntax, MIT Press, Cambridge, MA

[14] Selkirk, E.O (1995) Sentence prosody: intonation, stress, phrasing. In The handbook of phonological theory, ed. John A. Goldsmith. Blackwell: Cambridge

[15] Silverman, K. M. Beckman et al. (1992). ToBI: A standard for labeling English prosody. In Proceedings, 2nd International. Conference. on Spoken Language Processing 2, 867870. Banff, Canada 